\title{
LESSON 30
}

Display in Columns

Horizontal Display

Although 3 spaces are suggested, any number can be left.

Study this display which we are going to type on A4 paper $(210 \times 297 \mathrm{~mm})$.

$$
\text { Timber }
$$

(Leave two blank lines)

$\begin{array}{ll}\text { Ash } & \text { Pine } \\ \text { Elm } & \text { Spruce } \\ \text { Larch } & \text { Teak } \\ \text { Oak } & \text { Willow }\end{array}$

Step 1 Clear margins and tabs. Without putting the paper into the machine find the middle of the width of the page by measuring (Pica 41 or Elite 50 as a rule).

Step 2 To find the starting point of all the words in the first and second columns backspace once for every two letters in the longest word in each column and the spaces between the columns. We will agree to leave 3 spaces between the columns.

In the first column the longest word is Larch; in the second we can use either Spruce or Willow as they are the same length.

Step 3 To find the starting point for the first column backspace:

La rc $h$ (and the first space) next two spaces Wi II ow

Step 4 You should be at Pica 34 or Elite 43 if you started at Pica 41 or Elite 50. Set your left-hand margin at this point.

Step 5 To find the starting point for the second column tap out on the space bar all the letters in the longest word in the first column and the 3 spaces between.

Tap out:

\section{Larch and 3 spaces}

Step 6 If your first tab was at Pica $\mathbf{3 4}$ or Elite $\mathbf{4 3}$ you should now be at Pica $\mathbf{4 2}$ or Elite 51 . Set a tab at this point.

Step 7 Insert your paper and turn up 7 spaces. Centre the title 'Timber'.

Step 8 To leave 2 blank lines after the title turn up 3 single-line spaces and at the margin type the first word in the first column 'Ash'.

Step 9 Press the tab bar and type the first word in the second column 'Pine'. Finish this display and clear all margins and tabs.

Tabulations 1-3

TARGET TIME: 10 minutes each table.

Leave 3 spaces between columns.

Underscore headings.

Always leave 2 blank lines after a heading.

Leave 7 single lines between each table.

\section{UNIT 8}

Tabulation 1

Metals

$\begin{array}{ll}\text { Aluminium } & \text { Pewter } \\ \text { Copper } & \text { Platinum } \\ \text { Gold } & \text { Silver } \\ \text { Lead } & \text { Zinc }\end{array}$

Tabulation 3

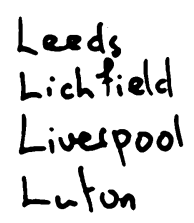

LESSON 30
Tabulation 2

\section{Sports}

$\begin{array}{ll}\text { Archery } & \text { Hockey } \\ \text { Bowls } & \text { Rounders } \\ \text { Cricket } & \text { Rugby } \\ \text { Football } & \text { Squash }\end{array}$

\section{TOWNS}

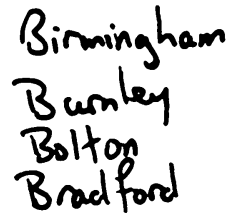

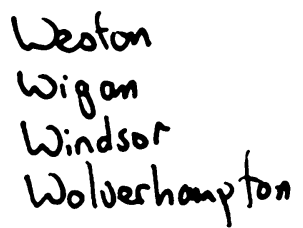

